\title{
Levels of slgA and LF against Candida spp. in the saliva of patients with complete dentures, lined with silicone-based elastic materials
}

\section{Mariana Yankova ${ }^{1}$, Vesela Lozanova ${ }^{2}$, Anelia Vasileva ${ }^{2}$, Bozhidar Yordanov ${ }^{3,}$ Valentin Lozanov ${ }^{4}$, Radoslav Baykuchev ${ }^{5}$, Vessela Raykova ${ }^{6}$, Ivan Mitov ${ }^{7}$}

1. Assistant Professor, Department of Prosthetic Dental Medicine, Faculty of Dental Medicine, Medical University - Sofia, Bulgaria;

2. Assistant Professor, Department of Medical Chemistry and Biochemistry, Faculty of Medicine, Medical University - Sofia, Bulgaria;

3. Professor, Head of Department of Prosthetic Dental Medicine, Faculty of Dental Medicine, Medical University - Sofia, Bulgaria

4. Associate Professor, Department of Medical Chemistry and Biochemistry, Faculty of Medicine, Medical University - Sofia, Bulgaria

5. Assistant Professor, Department of Medical Microbiology, Faculty of Medicine, Medical University - Sofia, Bulgaria

6. Associate Professor, Department of Medical Microbiology, Faculty of Medicine, Medical University - Sofia, Bulgaria

7. Professor, Head of Department of Medical Microbiology, Faculty of Medicine, Medical University - Sofia, Bulgaria 


\begin{abstract}
Introduction: Totally edentulous patients require a specific approach to prosthetic treatment, due to presence of excessive bone resorption, painful neurogenic spots and thin mucosa. One possible approach to treatment is application of complete dentures, lined with elastic materials. The porous structure of these materials is a prerequisite for bacterial and fungal colonization in oral cavity. The saliva flow, through its cleansing and antibacterial action, partly regulates this process due to the presence of histidine-rich peptides, peroxidase system, lysozyme, lactoferrin, slgA etc.
\end{abstract}

Aim: Investigation of the relation between sIgA or LF levels and the type and amount of Candida spp. in saliva of totally edentulous patients, treated with conventional and two-layer complete dentures.

Material and methods: 43 totally edentulous patients at the average age of $68.4 \pm 9.94$ years were treated with conventional complete dentures and with complete dentures, lined with silicone-based elastic materials. In relation to Candida spp. presence in the saliva, the patients were divided into three groups, as follows: without Candida presence, with norm/light presence and with moderate/heavy presence of Candida spp. The salivary levels of LF, slgA, and the amount and type of Candida spp. were examined before and after prosthetic treatment.

Results: We found dependence between LF levels and the type and amount of Candida spp. in saliva. The increase of LF concentration was established in the presence of non-albicans Candida and in the presence of Candida spp in levels below and above $10^{4} \mathrm{CFU} / \mathrm{ml}$ in saliva. Such dependence at slgA levels was not detected.

Conclusion: Despite the major role of slgA in the mucosal immune system, its levels were not dependent on the type and amount of Candida spp. in saliva, unlike those of LF.

Keywords: Lactoferin, slgA, saliva, soft denture liner, two-layer complete dentures, immunomodulatory function, Candida spp.

\title{
Introduction
}

Totally edentulous patients require a specific approach to prosthetic treatment, by reasons of presence of excessive bone resorption, painful neurogenic spots, as well as thin and non-persistent mucosa. One possible approach to prosthetic treatment is application of two-layer complete dentures (complete dentures, lined with elastic materials). The porous structure of these materials, however, creates a prerequisite for them to be a field for bacterial and fungal colonization in oral cavity (1). 
The saliva flow, through its cleansing and antibacterial action, can regulate this process to some extent. Antibacterial activity of saliva is associated with the presence of proteins - histidine-rich peptides, peroxidase system, lysozyme, lactoferrin, slgA etc. The mucosal immune system plays an important role in protecting the human body not only as an immune barrier but also as a regulator of potential inflammatory reactions. Its major component is the secretory $\lg \mathrm{A}(\mathrm{s} \lg \mathrm{A})$ used to assess the immune status of the oral mucosa (2).

Some authors (3) found higher levels of slgA in saliva in the presence of Candida spp., others reported that there was no relation between slgA values and the presence or absence of fungi in the oral cavity (4, $5,6)$. Mahajan et al. (7) reported a decrease in slgA levels in pseudomembranous oral candidiasis, as well as that the slgA values in Candida non-albicans were higher than these of $C$. albicans.

Lactoferrin (LF) is a non-enzyme glycoprotein of the transferrin family, with high affinity towards iron, and is found in the exocrine glands' secretions and in specific neutrophils granules at the sites of infection and inflammation (8), which is why it is used as a biomarker in a number of local and systemic diseases.

It has been established that LF has fungicidal, antiviral and anti-inflammatory effects (9-13), as well as immunomodulatory function (14). The human LF induces apoptosis in Candida cells and increased production of reactive oxygen species (ROS) (15). It regulates the expression of mediators of innate immunity, which subsequently affects the adaptive immune response (14).

The aim of the current study was to investigate the relation between SIgA and LF levels and the type and amount of Candida spp. in saliva of totally edentulous patients, treated with conventional and two-layer complete dentures.

\section{Materials and methods}

\section{Selection and distribution of the Patients}

In the Faculty of Dental Medicine - Sofia, 43 patients (12 men and 31 women) between the age of 48 and 90 years (average age of $68.4 \pm 9,94$ years) were treated with conventional complete dentures $(n=15)$, with complete denture, lined with heat-polymerized silicone-based elastic material [Molloplast B (Detax, Germany)], $(n=15)$ and with complete denture lined with auto-polymerized silicone-based elastic material [Megabase (Dreve, Germany)], $(n=13)$.

All of the patients were divided into three groups in relation to Candida spp. presence in the saliva - group without Candida spp. presence, with norm/light presence and with moderate/heavy presence of Candida spp.

\section{Selection of patients - criteria for elimination}

The following patients were not included in the research: patients with systemic diseases (asthma, diabetes Type I, uncontrolled diabetes Type II, Sjogren's Syndrome, conditions of immunodeficiency), patients who had used antibiotics in the previous 3 months, patients who had undergone radiotherapy or 
chemotherapy in the previous six months and ones diagnosed with denture stomatitis as a result of wearing old removable dentures.

\section{Collection of saliva}

A sample of whole unstimulated saliva for biochemical and microbiological analysis was taken from all patients before and at the third month after prosthetic treatment. During the collection of saliva the patients were seated comfortably on the dental chair with his (her) head tilted slightly forward. The samples were taken by the method of A. Vissink (16) always in the morning between 09:00 and 12:00 and the patients had been preliminary instructed not to eat, consume liquids or smoke before the collecting, and not to rinse their mouths with antiseptic solutions in the last 2 hours. The necessary quantity of saliva (around $0.5 \mathrm{ml}$ ) was collected in sterile containers by the method of spitting (the patients gathered saliva at the bottom of their oral cavity and spitted it at intervals of $60 \mathrm{~s}$ ), whereas the first portion (the so called dead saliva) was discarded. The samples were stored in a refrigerator at $4^{\circ} \mathrm{C}$ and carried to the microbiological laboratory in a cooler bag.

Prior to saliva collection for biochemical analysis, patients rinsed their mouth with deionized water. The required amount of about $2 \mathrm{ml}$ was placed in a crio-test tube. The biological samples were immediately frozen in liquid nitrogen and stored at $-70^{\circ} \mathrm{C}$ until the analysis was conducted.

\section{Analysis of lactoferrin (LF) and immunoglobulin A (IgA) levels in saliva}

For the quantitative determination of lactoferrin and IgA levels were used commercial ELISA kits (Human Lactoferrin ELISA kit and Human IgA ELISA kit, both from MyBioSource,Inc, San Diego, CA, USA) and the analyses were performed following the manufacturer's protocols. Using the results for the calibration standards provided in the kits were constructed standard quadratic curves for Lactoferrin and for $\lg A\left(R^{2}=\right.$ 0.9702 and $R^{2}=0.9968$, respectively) and the amounts of Lactoferrin and IgA in the biological samples were calculated based on the respective equations. The amount of Lactoferrin and IgA in the analyzed biological samples is expressed as $\mu \mathrm{g} / \mathrm{ml}$ and represents the mean value of two independent measurements. All data are expressed as mean \pm SEM.

\section{Microbiological analysis \\ Detection, identification and semi-quantitative estimation of Candida spp. in saliva}

All collected samples were inoculated in chromogenic agar for the isolation and identification of Candida spp. Chrom agar Candida (BioMerieux). The inoculated materials were cultivated for 48 hours at temperature of $35^{\circ} \mathrm{C}$ in aerobic conditions. Identification of the isolated species was conducted by: direct identification of Candida albicans - recognizing is done directly from the chromatogenic environment by the green color of the colonies; all the rest of the Candida species were identified by using MALDI TOF spectrophotometric analysis - VITEK MS (BioMerieux). Semi-quantitative estimation of the isolated fungi was conducted (17). The identified species of Candida were written in the result in CFU/ml (Colony forming units/ml - colonies formed on one $\mathrm{ml}$, reflecting the number of living fungi). 
All patients signed informed consent form for participation in the present research. The scientific research was approved by the Research Ethics Commission “KENIMUS” (Statement № 21/2016).

For achieving standardization of the hygiene factor for the dentures, all patients included in the present research were freely provided with one and the same tablets for cleaning dentures (Protefix, Germany) for the whole period of observation (6 months).

For the statistical analysis we used a computer configuration SPSS version 19. For analysis of the results and for comparison of the examined parameters we used one-way Anova with post-hoc Tukey test, Student t-test with 95\% confidence interval $(p<0.05)$.

\section{Results}

In our study we investigated 43 totally edentulous patients. We have detected the presence of Candida spp. in the saliva of $24(55.8 \%)$ patients and the absence of Candida spp. in 19 patients (44.2\%). In the group of patients with Candida spp. in saliva, concentration of Candida spp. to $10^{4} \mathrm{CFU} / \mathrm{ml}$ was established in 18 patients (41.9\%), whereas concentration of Candida spp. over $10^{4} \mathrm{CFU} / \mathrm{ml}$ was detected in 6 patients $(13.9 \%)$. Our results displayed that in patients with Candida spp. over $10^{4} \mathrm{CFU} / \mathrm{ml}$ the salivary concentration of LF was lower in comparison with patients without Candida spp., $p=0.02$ (Tabl. 1)

Table 1. Values of LF and slgA relative to quantity of Candida spp.

\begin{tabular}{|c|c|c|c|c|c|c|}
\hline $\begin{array}{r}\text { Parameters } \\
\text { Candida quantity }\end{array}$ & & $\mathrm{LF} \mu \mathrm{g} / \mathrm{ml}$ & & & $\lg A \mu \mathrm{g} / \mathrm{ml}$ & \\
\hline time & before & after & $\mathrm{F} / \mathrm{p}$ & before & after & F/p \\
\hline Without Candida & $\begin{array}{l}0.278 \pm 0.007 \\
n=19 / 43 \\
(44.2 \%)\end{array}$ & $\begin{array}{l}0.280 \pm 0.007 \\
n=13 / 43 \\
(30.2 \%)\end{array}$ & $\begin{array}{l}t=-0.192 \\
p=0.85\end{array}$ & $\begin{array}{l}161.895 \pm 4.627 \\
n=19 / 43 \\
(44.2 \%)\end{array}$ & $\begin{array}{l}154.969 \pm 3.916 \\
n=13 / 43 \\
(30.2 \%)\end{array}$ & $\begin{array}{l}t=1.069 \\
p=0.29\end{array}$ \\
\hline $\begin{array}{l}\text { Norm and Light } \\
\text { presence } \\
\text { to } 10^{4} \mathrm{CFU} / \mathrm{ml}\end{array}$ & $\begin{array}{l}0.267 \pm 0.005 \\
n=18 / 43 \\
(41.9 \%)\end{array}$ & $\begin{array}{l}0.273 \pm 0.006 \\
n=19 / 43 \\
(44.2 \%)\end{array}$ & $\begin{array}{l}t=-2.542 \\
p=0.02^{\star}\end{array}$ & $\begin{array}{l}166.956 \pm 5.788 \\
n=18 / 43 \\
(41.9 \%)\end{array}$ & $\begin{array}{l}157.329 \pm 5.582 \\
n=19 / 43 \\
(44.2 \%)\end{array}$ & $\begin{array}{l}t=1.197 \\
p=0.24\end{array}$ \\
\hline $\begin{array}{l}\text { Moderate and } \\
\text { heavy presence } \\
\text { over } 10^{4} \mathrm{CFU} / \mathrm{ml}\end{array}$ & $\begin{array}{l}0.243 \pm 0.006 \\
n=6 / 43 \\
(13.9 \%)\end{array}$ & $\begin{array}{l}0.271 \pm 0.005 \\
n=11 / 43 \\
(25.6 \%)\end{array}$ & $\begin{array}{l}t=-2.977 \\
p=0.009^{*}\end{array}$ & $\begin{array}{l}161.874 \pm 10.655 \\
n=6 / 43 \\
(13.9 \%)\end{array}$ & $\begin{array}{l}160.749 \pm 4.041 \\
n=11 / 43 \\
(25.6 \%)\end{array}$ & $\begin{array}{l}t=0.119 \\
p=0.91\end{array}$ \\
\hline F/p & $\begin{array}{l}F(2 / 40)=4.202 \\
p=0.02^{*}\end{array}$ & $\begin{array}{l}F(2 / 40)=0.516 \\
p=0.60\end{array}$ & & $\begin{array}{l}F(2 / 40)=0.256 \\
p=0.78\end{array}$ & $\begin{array}{l}F(2 / 40)=0.270 \\
p=0.77\end{array}$ & \\
\hline $\begin{array}{l}\text { p Tukey HSD } \\
\text { Test between } \\
\text { groups }\end{array}$ & $p_{(1-3)}=0.02^{*}$ & NS & & NS & NS & \\
\hline
\end{tabular}

After prosthetic treatment, the number of patients with Candida spp. increased by $25 \%$ (from 24 to 30), mostly in patients treated with complete dentures lined with elastic materials. The number of patients with 
Candida spp. to $10^{4} \mathrm{CFU} / \mathrm{ml}$ increased from 18 to 19 , while with Candida spp. over $10^{4} \mathrm{CFU} / \mathrm{ml}$ the number increased approximately twice - from 6 to 11 patients, (Tabl.1).

We established that after prosthetic treatment the salivary concentration of LF did not change in patients without Candida spp., whereas in patients with Candida spp. to and above $10^{4} \mathrm{CFU} / \mathrm{ml}$ was significantly increased, $p=0.02 ; p=0.009$, respectively, (Tabl. 1)

A detailed study of the type of Candida spp, showed a statistically significant increase in salivary LF concentration after prosthetic treatment in patients with non-albicans Candida in saliva, $p=0.03$ (Tabl. 2).

Table 2. Values of LF and slgA relative to type of Candida

\begin{tabular}{|c|c|c|c|c|c|c|}
\hline \multicolumn{7}{|c|}{ Parameters } \\
\hline \multirow{2}{*}{$\begin{array}{r}\begin{array}{r}\text { Candida } \\
\text { type }\end{array} \\
\text { time }\end{array}$} & \multicolumn{3}{|c|}{$\mathrm{LF} \mu \mathrm{g} / \mathrm{ml}$} & \multicolumn{3}{|c|}{$\operatorname{slg} A \mu g / m l$} \\
\hline & before & after & F/p & before & after & F/p \\
\hline \multirow{2}{*}{$\begin{array}{l}\text { Without } \\
\text { Candida }\end{array}$} & $0.278 \pm 0.007$ & $0.280 \pm 0.007$ & $t=-0.192$ & $161.895 \pm 4.627$ & $154.969 \pm 3.916$ & $t=1.069$ \\
\hline & $\begin{array}{l}n=19 / 43 \\
(44.2 \%)\end{array}$ & $\begin{array}{l}n=13 / 43 \\
(30.2 \%)\end{array}$ & $p=0.85$ & $\begin{array}{l}n=19 / 43 \\
(44.2 \%)\end{array}$ & $\begin{array}{l}n=13 / 43 \\
(30.2 \%)\end{array}$ & $p=0.29$ \\
\hline \multirow{2}{*}{$\begin{array}{l}\text { Candida } \\
\text { albicans }\end{array}$} & $0.261 \pm 0.008$ & $0.275 \pm 0.008$ & $t=-1.146$ & $171.383 \pm 9.039$ & $158.595 \pm 4.818$ & $t=1.209$ \\
\hline & $\begin{array}{l}n=11 / 43 \\
(25.6 \%)\end{array}$ & $\begin{array}{l}n=13 / 43 \\
(30.2 \%)\end{array}$ & $p=0.26$ & $\begin{array}{l}n=11 / 43 \\
(25.6 \%)\end{array}$ & $\begin{array}{l}n=13 / 43 \\
(30.2 \%)\end{array}$ & $p=0.24$ \\
\hline \multirow{2}{*}{$\begin{array}{l}\text { Non- } \\
\text { albicans } \\
\text { Candida }\end{array}$} & $0.261 \pm 0.005$ & $0.274 \pm 0.005$ & $t=-2.238$ & $160.865 \pm 5.145$ & $151.372 \pm 4.719$ & $\mathrm{t}=1.350$ \\
\hline & $\begin{array}{l}n=13 / 43 \\
(30.2 \%)\end{array}$ & $\begin{array}{l}n=17 / 43 \\
(39.5 \%)\end{array}$ & $p=0.03^{*}$ & $\begin{array}{l}n=13 / 43 \\
(30.2 \%)\end{array}$ & $\begin{array}{l}n=17 / 43 \\
(39.5 \%)\end{array}$ & $p=0.09$ \\
\hline \multirow[t]{2}{*}{$F / p$} & $F(2 / 40)=2.622$ & $F(2 / 40)=0.241$ & & $F(2 / 40)=0.794$ & $F(2 / 40)=0.640$ & \\
\hline & $p=0.08$ & $p=0.79$ & & $p=0.46$ & $p=0.53$ & \\
\hline
\end{tabular}

In our study we did not establish differences in salivary levels in slgA neither before nor after prosthetic treatment in the investigated experimental groups (Tabl. 1; Tabl. 2)

\section{Discussion:}

The mucosal immune system is a multifunctional protective network, whose main role is to maintain oral homeostasis. The study of LF and slgA levels as well as its relation to the presence of Candida spp. in the saliva of totally edentulous patients, especially these treated with dentures, lined with elastic materials, is performed for the first time in our country. The available experimental result show only interrelation between salivary levels of Candida spp., with LF and slgA in various local and systemic diseases (2 - 8, 10, 13). The enhanced number of patients with Candida spp. in saliva after prosthetic treatment established in our study, confirms the concept that the surface characteristics of the elastic materials used 
for lining dentures (porosity and final hardness) are a prerequisite for bacterial and fungal colonization $(18,19)$.

Despite the main role of slgA in the function of mucosal immune system, our results confirmed previously reported in other studies $(4,5,6)$ lack of relation between slgA levels and the presence of Candida spp. in saliva. In contrast to higher levels of sigA in the presence of Candida spp. in saliva, established by Thaweboon et al. (3), our results displayed not statistically significant tendency to decrease slgA concentration at elevated levels of Candida spp., after prosthetic treatment. Our results are more in agreement with those reported by Mahajan et al. (7), which found lower slgA values in patients with candidiasis. On the other hand, the significant differences in slgA levels among patients with Candida albicans and non-albicans Candida, established by the authors mentioned above (7) did not find confirmation in our study. However, we should note that Mahajan et al. (7) investigate immunosuppressed patients with candidiasis, unlike us. The significant differences established in present study in the salivary LF concentration in patients with different levels of Candida spp. before prosthetic treatment are corresponding with the results reported by Alves et al. (10). Our results did not establish relation between level of LF and species of Candida. We did not find such experimental data in scientific literature. We suppose that the established increase of LF levels three months after prosthetic treatment in patients with non-albicans Candida in saliva may be due to its more pronounced stimulating effect in comparison to Candida albicans on the immunomodulatory and fungicidal properties of LF or to be an expression of its ability to influence inflammatory processes, cell proliferation and differentiation. Increasing LF levels three months after depilation in patients with non-albicans Candida may be due to the more pronounced stimulant effect of this fungus as compared to $C$. albicans on the immunomodulatory and fungicidal properties of LF or to be an expression of its ability to influence inflammatory processes, cell proliferation and differentiation. These LF properties may be the cause of a lack of marked clinical manifestations of denture stomatitis, despite the increase in the amount of Candida spp. in patients who were treated with two-layer dentures. The rise in LF levels in saliva for a short time period (3 months) after prosthetic treatment may be an expression of its anti-inflammatory properties or of a specific immune response against a particular type of microorganisms, whereas high or low levels of LF after long period of prosthetic treatment could be a result of strong immune response or of weak immunity.

\section{Conclusion:}

The presence of elastic lining materials in the oral cavity increased the amount of Candida spp. in saliva. Despite the main role of slgA in the mucosal immune system, its levels were not dependent on the type and amount of Candida spp. in saliva, unlike those of LF. LF levels in unstimulated whole saliva can be used as an indicator for the presence of Candida spp. (predominantly non-albicans Candida) in saliva, but necessarily consistent with the time since the last prosthetic treatment.

\section{Acknowledgements:}

The authors thank Dr. Boyanka Pavlova, the Medical-Diagnostic Laboratory Cibalab Ltd., Department of Microbiology for the assistance provided in the research. 
The authors thank Queisser Pharma, Germany for the free of charge denture tablets for all patients throughout the study.

This study is financially supported through Research Project № 5085/2016 from the Medical University Sofia, Bulgaria.

\section{References}

1. Basker R.M., Davenport J.C., Thomason J. M. Prosthetic Treatment of the Edentulous Patient. Blackwell Publishing Company, Fifth edition, 2011, 214-218, 224-226, 228-244.

2. Krasteva-Panova A.Z. General unstimulated saliva as a diagnostic medium for immuneinflammatory diseases and oral neoplasms. Dissertation [in Bulgarien], Sofia, 2009, 13-15.

3. Thaweboon S, Thaweboon B, Nakornchai S, Jitmaitree S. Salivary secretory IgA, pH, flow rates, mutans streptococci and Candida in children with rampant caries. Southeast Asian J Trop Med Public Health. 2008;39(5):893-899.

4. Kurnatowska A, Magnowski J. Analysis of slgA concentrations in the contents of the cervical canal of the uterus and of the oral cavity in women with Candida or without fungi in ontocenoses of these organs. [Article in Polish]. Wiad Parazytol. 2002;48(3):271-276.

5. Belazi M, Fleva A, Drakoulakos D, Panayiotidou D. Salivary IgA and serum IgA and IgG antibodies to Candida albicans in HIV-infected subjects. Int J STD AIDS. 2002;13(6):373-377.

6. Rashkova $\mathrm{M}$ et al. Secretory Immunoglobulin A (S-IgA) and the Oral Risk Markers: Quality of Saliva, Dental Biofilm, Oral Candida and Lactobacillus spp. OHDMBSC. 2009, VIII(3), 11-18.

7. Mahajan B, Bagul N, Desai R, Reddy M, Mahajan A, Shete A, Risbud A, Mane A. Pseudomembranous Type of Oral Candidiasis is Associated with Decreased Salivary Flow Rate and Secretory Immunoglobulin A Levels. Mycopathologia. 2015;180(1-2):75-80.

8. Berlutti F, Pilloni A, Pietropaoli M, Polimeni A, Valenti P. Lactoferrin and oral diseases: current status and perspective in periodontitis. Annali di Stomatologia. 2011; 2(3-4):10-18.

9. Komatsu A, Satoh T, Wakabayashi H, Ikeda F. Effects of bovine lactoferrin to oral Candida albicans and Candida glabrata isolates recovered from the saliva in elderly people. Odontology. 2015;103(1):50-55.

10. Alves TP, Simxes AC, Soares RM, Moreno DS, Portela MB, Castro GF. Salivary lactoferrin in HIV-infected children: correlation with Candida albicans carriage, oral manifestations, HIV infection and its antifungal activity. Arch Oral Biol. 2014;59(8):775-782.

11. Mishra B, Leishangthem GD, Gill K, Singh AK, Das S, Singh K, Xess I, Dinda A, Kapil A, Patro IK, Dey S. A novel antimicrobial peptide derived from modified $\mathrm{N}$-terminal domain of bovine lactoferrin: design, synthesis, activity against multidrug-resistant bacteria and Candida. Biochim Biophys Acta. 2013;1828(2):677-686.

12. Al-Sheikh $\mathrm{H}$. Effect of lactoferrin and iron on the growth of human pathogenic Candida species. Pak J Biol Sci. 2009;12(1):91-94.

13. Orsi N. The antimicrobial activity of lactoferrin: current status and perspectives. Biometals. 2004;17(3):189-196.

14. Nikolova M, Nikolov P, Baleva M. Lactoferrin in Clinical Practice. [Article in Bulgarien] Medical review. 2014;50(3):65-68.

15. Andrés MT, Viejo-Díaz M, Fierro JF. Human lactoferrin induces apoptosis-like cell death in Candida albicans: critical role of $\mathrm{K}+$-channel-mediated $\mathrm{K}+$ efflux. Antimicrob Agents Chemother. 2008;52(11):4081-4088.

16. Karova E. Saliva - factor for maintaining of the oral homeostasis. [Book in Bulgarien] 2013:26-53.

17. Fujitani S, Cohen-Melamed MH, Tuttle RP, Delgado E, Taira Y, Darby JM. Comparison of semiquantitative endotracheal aspirates to quantitative non-bronchoscopic bronchoalveolar lavage in diagnosing ventilator-associated pneumonia. Respir Care. 2009; 54(11):1453-61. 
18. Chaves CA et al.: Cytotoxicity of denture base and hard chairside reline materials: A systematic review. J Prosthet Dent. 2012, 107(2), 114-127

19. Mese A., Guzel KG.: Effect of storage duration on the hardness and tensile bond strength of silicone- and acrylic resin-based resilient denture liners to a processed denture base acrylic resin. J Prosthet Dent. 2008, 99(2), 153-158.

\section{Corresponding author:}

Mariana Yankova,

Department of Prosthetic Dental Medicine,

Faculty of Dental Medicine,

Medical University,

1 G. Sofiiski Str.,

Sofia, Bulgaria

email: m.jankova@abv.bg 